\title{
The therapeutic potential of escitalopram in the treatment of panic disorder
}

\author{
Mark H Townsend \\ Erich J Conrad \\ Department of Psychiatry, Louisiana \\ State University Health Sciences \\ Center New Orleans, New Orleans, \\ Louisiana, USA
}

\begin{abstract}
Panic disorder is a chronic and disabling condition that is often accompanied by other psychiatric and medical conditions. The serotonin reuptake inhibitors (SSRIs) and serotoninnorepinephrine reuptake inhibitors (SNRIs) have been used effectively with panic disorder (PD) and conditions in which panic attacks frequently occur. Escitalopram is the most selective SSRI and a variety of evidence suggests it is of great value in the treatment of panic disorder. In this paper, we review the theoretical and practical implications of its use.
\end{abstract}

Keywords: panic disorder, escitalopram, antidepressant, serotonin

\section{Introduction}

Panic disorder is a common and frequently chronic illness that often co-occurs with other psychiatric and medical conditions. For example, the National Comorbidity Survey-Replication study reported a 2.7\% 12-month, and a 4.7\% lifetime, prevalence (Kessler, Berglund et al 2005; Kessler, Chiu et al 2005). Panic disorder often accompanies general medical as well as psychiatric conditions (Simon and Fischmann 2005). Patients with panic disorder are at an increased risk for suicide (Goodwin and Roy-Byrne 2006), which appears to increase with comorbid depression (Black 1995). Panic disorder is also associated with autonomic instability, also worsened when depression is present (Townsend 1998).

Much evidence suggests that the selective serotonin uptake inhibitor (SSRI) escitalopram is effective in the treatment of panic disorder (PD). The tricyclic antidepressants (TCAs) and MAO inhibitors (MAOIs) are also effective in this population (Garakoni et al 1984). However, TCAs are associated with potentially fatal arrhythmias, either in monotherapy or in combination with fluoxetine (Witchel et al) and MAO inhibitors must be used with caution in many populations (Yamada and Yasuhara 2004). In this review, we consider neurobiological evidence that supports the use of escitalopram in PD and the clinical trials that have been performed with escitalopram in the treatment of anxiety.

\section{Neurobiological considerations}

While numerous interacting neuroanatomical sites have been implicated in the pathogenesis of $\mathrm{PD}$, a dysfunction of the serotonin (5-HT) system appears to play a crucial role in development and perpetuation of panic attacks (Grove 1997; Maron 2006). The selective SSRIs and the serotonin-norepinephrine reuptake inhibitors (SNRIs) have demonstrated efficacy in the treatment of panic disorder, as well as conditions frequently comorbid with it, including major depression, generalized anxiety disorder, post-traumatic stress disorder, social anxiety disorder and obsessivecompulsive disorder (Pollack 2005). SSRIs and SNRIs, in contrast with tricyclic antidepressants, monoamine oxidase inhibitors and benzodiazepines, hold more favorable side effect profiles and a lower likelihood of drug interaction (Lader 2005). 
Research into the mechanisms underlying fear and avoidance has implicated the serotonergic and noradrenergic systems in specific locations (Goddard 1997; Grove 1997; Gorman 2000; Ninan 2005). Several models integrate the panic response through the amygdala, with projections to the hypothalamus, locus ceruleus, periaqueductal gray region, parabrachial nucleus and thalamus (Gorman 2000). While the role of 5-HT in panic disorder is clearly important, researchers report conflicting evidence about whether the condition represents a state of 5-HT deficiency or excess (Maron 2006). Serotonin has an inhibitory effect within three brain systems: the noradrenergic activity of the locus ceruleus, the defense and escape behaviors mediated by the periaqueductal gray region, and the production of corticotrophin releasing factor (CRF) by the hypothalamus. SSRIs can produce an anti-panic activity through these mechanisms over time by reducing the "downstream manifestations of panic" (Gorman 2000).

Furthermore, the 5-HT1A auto-receptor is believed to play a role in counteracting the acute increase of serotonin after SSRI initiation, and it may be implicated in an elevated perception of somatic anxiety (Ceglia 2004; Sullivan 2005). Further research is needed to determine if escitalopram, highly potent at serotonin reuptake inhibition, is capable of producing a clinically significant anxiolytic effect more rapidly than other agents in the SRRI class.

\section{Clinical trials with citalopram in panic disorder}

Although research into escitalopram as treatment for panic disorder per se has been relatively sparse, it has been shown to be effective in a number of anxiety disorders. Furthermore, escitalopram is the S-enantiomer of citalopram, a compound that is FDA-approved only for major depression, but which has demonstrated efficacy in panic disorder in several controlled trials (Wade et al 1997; Lepola et al 1998; Perna et al 2001).

In the 1997 Wade trial, for example, a large sample of PD subjects were randomized to placebo, citalopram, and the tertiary tricyclic clomipramine, the latter itself effective for PD (Cassano et al 1988). Subjects were followed for 8 weeks, and those given clomipramine at 60 or $90 \mathrm{mg} /$ day and citalopram at doses between 20 to $60 \mathrm{mg} /$ day had fewer panic attacks than on placebo. Interestingly, and perhaps suggestive of a negative effect of the R-enantiomer, citalopram at lower doses at end-of-trial had fewer panic attacks than the higherdosed subjects. Some have suggested that the presence of the R-enantiomer reduces the efficacy of citalopram, whose anxiolytic and antidepressant effects are the result of escitalopram (Sanchez et al 2003).
Escitalopram itself is effective in generalized anxiety disorder (Davidson 2004; Baldwin and Nair 2005), which is frequently comorbid with panic disorder and in which panic attacks often occur. Social anxiety disorder is often accompanied by situational panic attacks, and escitalopram has been demonstrated to reduce social phobia symptoms (Lader et al 2004). In addition, studies of escitalopram in depression have shown a reduction in concurrent anxiety (Burke et al 2002; Olie et al 2006).

\section{Clinical trials with escitalopram in panic disorder}

The literature contains three studies of varying rigor and intent that examine escitalopram in primary panic disorder (Stahl et al 2003; Sayer and Cetin 2004; Rampello et al 2006). The small, open-label Sayer and Cetin trial found escitalopram useful, but was presented as a poster and available only as an abstract. Both the Stahl and Rampello studies were designed to discriminate clinical outcome in PD patients taking either citalopram or escitalopram. In animal models, R-citalopram has appeared to counteract the antidepressant effect of escitalopram (Mansari et al 2007), thus the hypothesis that citalopram may be less effective than its S-enantiomer.

The Stahl study was a randomized, double-blind, placebo-controlled, 10-week trial with 366 adults with PD. Patients were randomized to escitalopram at 10 to $20 \mathrm{mg}$ daily; citalopram, 20 to $40 \mathrm{mg}$ daily; or placebo. While citalopram and escitalopram were more effective than placebo in reducing both anticipatory anxiety and the frequency and intensity of panic attacks, escitalopram subjects separated from placebo on one measure earlier than those taking citalopram. On the Panic and Agoraphobia scale, escitalopram showed significant improvement relative to placebo from week four onwards, whereas citalopram results did not obtain significance until week eight.

Although the Rampello study also attempted to show the superiority of escitalopram, it had fewer, older subjects than Stahl's and followed an open-label, naturalistic design. Forty men and women age 65 and older with panic disorder were assigned to either $10 \mathrm{mg}$ escitalopram or $20 \mathrm{mg}$ citalopram each day for 8 weeks. Although panic attack frequency was equivalently reduced in both groups, the escitalopram group showed fewer panic attacks at week 2, while the citalopram group separated from baseline panic attack numbers at week 4 . The open-label nature of the Rampello trial hinders generalization of its results, however it does serve to underscore the effectiveness of both escitalopram and citalopram in this population. 


\section{Safety and tolerability}

Stahl confirmed the generally benign adverse event and safety profile of escitalopram demonstrated in depression trials (Hirschfeld 2004). The rate of discontinuation due to adverse events for escitalopram was $6.3 \%$ compared to $7.6 \%$ for placebo. Most treatment-emergency adverse events reported with escitalopram in major depression (Lexapro [package insert] 2007) are common to other SRIs. Sexual side effects, such as delayed ejaculation and anogasmia, and gastrointestinal symptoms, including nausea and diarrhea, have been ascribed to SRI agonism at the 5-HT2 and 5-HT3 receptors, respectively (Stahl 1998). As with all SRIs, clinicians must be alert to the possibility of iatrogenic mania (Goldbert and Truman 2003), as well as suicidal ideation or behavior, especially at treatment initiation (Bridge et al 2007).

\section{Conclusion}

Many lines of evidence predict that a highly selective SSRI like escitalopram would be effective in PD, and several clinical trials with other anxiety disorders and in "anxious" depression support its first-line use. As PD often presents concurrently with other anxiety disorders and major depression, escitalopram has the potential to reduce numerous related symptoms. Its favorable tolerability predicts successful initiation and maintenance of treatment in PD, and its safety profile supports its use in individuals with concomitant general medical conditions.

\section{References}

Baldwin DS, Nair RV. 2005. Escitalopram in the treatment of generalized anxiety disorder. Expert Review of Neurotherapeutics, 5:443-9.

Black DW, Wesner R, Bowers W, et al. 1995. Acute treatment response in outpatients with panic disorder: high versus low depressive symptoms. Ann Clin Psychiatry, 7:181-8.

Bridge JA, Iyengar S, Salary CB, et al. 2007. Clinical response and risk for reported suicidal ideation and suicide attempts in pediatric antidepressant treatment. JAMA, 297:1683-96.

Burke WJ, Gergel I, Bose A. 2002. Fixed dose trial of the single isomer SSRI escitalopram in depressed outpatients. J Clin Psychiatry, 63:331-6.

Cassano GB, Petracca A, Perugi G, et al. 1988. Clomipramine for panic disorder: the first 10 weeks of along-term comparisons with imipramine. $J$ Affect Disord.

Ceglia I, Acconcia S, Fracasso C, et al. 2004. Effects of chronic treatment with escitalopram or citalopram on extracellular 5-HT in the prefrontal cortex of rats: role of the 5-HT1A Receptors. British Journal of Pharacology, 142:469-78.

Cowley DS, Ha EH, Roy-Byrne PP. 1997. Determinants of pharmacologic treatment failure in panic disorder. J Clin Psychiatry, 58:555-61.

Davidson JR, Bose A, Korotzer A, et al. 2004. Escitalopram in the treatment of generalized anxiety disorder: double-blind, placebo-controlled, flexible-dose study. Depression and Anxiety, 19:234-40.

Garakoni H, Zitirin CM, Klein DF. 1984. Treatment of panic disorder with imipramine alone. Am J Psychiatry, 141:446-8.
Goldberg JF, Truman CJ. 2003. Antidepressant-induced mania: an overview of current controversies. Bipolar Dis, 5:407-20.

Goddard AW, Charney DS. 1997. Toward an integrated neurobiology of panic disorder. J Clin Psychiatry, 58 (Suppl 2):4-11.

Goodwin RD, Roy-Byrne P. 2006. Panic and suicidal ideation and suicide attempts: results from the national comorbidity survey. Depress Anxiety, 23:124-32.

Gorman JM, Kent JM, Sullivan GM, et al. 2000. Neuroanatomical hypothesis of panic disorder, revisited. Am J Psychiatry, 157:493-505.

Grove G, Coplan JD, Hollander E. 1997. The neuroanatomy of 5-HT dysregulation and panic disorder. $J$ of Neuropsychiatry and Clin Neurosciences, 9:198-207.

Hirschfeld RMA, Vornik LA. 2004. Newer antidepressants: review of efficacy and safety of escitalopram and duloxetine. J Clin Psychiatry, 65(Suppl 4):46-52.

Hogg S, Michan L, Jessa M. 2006. Prediction of anti-panic properties of escitalopram in the Dorsal Periaqueductal Grey Model of Panic Anxiety. Neuropharmacology, 51:141-5.

Kessler RC, Berglund P, Demler O, et al. 2005. Lifetime Prevalence and Age-of-Onset Distributions of DSM-IV Disorders in the National Comorbidity Survey Replication. Arch Gen Psychiatry, 62:593-602.

Kessler RC, Chiu WT, Demler O, et al. 2005. Prevalence, Severity, and Comorbidity of 12-Month DSM-IV Disorders in the National Comorbidity Survey Replication. Arch Gen Psychiatry, 62:617-27.

Lader M, Stender K, Burger V, et al. 2004. Efficacy and tolerability of escitalopram in 12- and 24-week treatment of social anxiety disorder. Depress Anxiety, 19:241-8.

Lader M. 2005. Management of panic disorder. Expert Rev of Neurother, 5:259-66.

Lepola UM, Wade AG, Leinonen EV. 1998. A controlled, prospective, 1 -year trial of citalopram in the treatment of panic disorder. $\mathrm{J} \mathrm{Clin}$ Psychiatry.

Lexapro [package insert]. 2007. St. Louis, MO: Forest Pharmaceuticals, Inc.

Mansari M, Wiborg O, Mnie-Filali O, et al. 2007. Allosteric modulation of the effect of escitalopram, paroxetine and fluoxetine: In-vitro and in-vivo studies. Int J Neuropsychopharmacol, 10:31-40.

Maron E, Shlik J. 2006. Serotonin Function in Panic Disorder: Important, But Why? Neuropsychopharmacology, 31:1-11.

Olie JP, Tonnoir B, Menard F, et al. 2006. A prospective study of escitalopram in the treatment of major depressive episodes in the presence or absence of anxiety. Depress Anxiety, Oct 13.

Perna G, Bertani A, Caldirola D, et al. 2001. A comparison of citalopram and paroxetine in the treatment of panic disorder: a randomized, singleblind study. Pharmacopsychiatry, 34:85-90.

Pollack MH, Marzol PC. 2000. Panic: course, complications and treatment of panic disorder. J Psychopharmacol, 14:S25-S30.

Pollack MH. 2005. The pharmacotherapy of panic disorder. J Clin Psychiatry, 66(Suppl 4):23-27.

Rampello L, Alvando A, Raffaele R, et al. 2006. New possibilities of treatment for panic attacks in elderly patients: escitalopram versus citalopram. J Clin Psychopharmacol, 26:67-70.

Sanchez C, Bergqvist PBF, Brennum LT, et al. 2003. Escitalopram, the $s-(+)$-enantiomer of citalopram, is a selective serotonin reuptake inhibitor with potent effects in animal models predictive of antidepressant and anxiolytic activities. Psychopharmacology, 167:353-62.

Sanchez C, Bogeso KP, Ebert B, et al. 2004. Escitalopram versus citalopram: the surprising role of the R-enantiomer. Psychopharmacology, 174:163-76.

Sayar MK, Cetin M. 2004. Escitalopram in panic disorder: an open flexibledose study. World J Biol Psychiatry, 5(Suppl 1):133.

Simon NM, Fischmann D. 2005. The implications of medical and psychiatric comorbidity with panic disorder. J Clin Psychiatry, 66(Suppl 4):8-15.

Stahl SM. 1998. Mechanism of action of serotonin selective reuptake inhibitors: serotonin receptors and pathways mediate therapeutic effects and side effects. $J$ Affect Disord, 51:215-25. 
Stahl SM, Gergel I, Li D. 2003. Escitalopram in the treatment of panic disorder: a randomized, double-blind, placebo-controlled trial. J Clin Psychiatry, 64:1322-27.

Sullivan GM, Oquendo MA, Simpson N, et al. 2005. Brain serotonin 1A receptor binding in major depression is related to psychic and somatic anxiety. Biol Psychiatry, 58:947-54.

Townsend MH, Bologna NB, Barbee JG. 1998. Heart rate and blood pressure in panic disorder, major depression, and comorbid panic disorder and major depression. Psychiatry Res, 79:187-90.
Wade AG, Lepola U, Koponen HJ, et al. 1997. The effect of citalopram in panic disorder. Br J Psychiatry, 170:549-53.

Witchel HD, Hancox JC, Hutt DJ. 2003. Psychotropic drugs, cardiac arrhythmia, and sudden death. J Clin Psychopharm, 23:58-77.

Yamada M, Yasuhara H. 2004. Clinical pharmacology of MAO inhibitors: safety and future. Neurotoxicol, 25:215-21. 